\title{
Randomised controlled trial of two methods of weaning from high frequency positive pressure ventilation
}

\author{
A GREENOUGH, J POOL, AND H GAMSU \\ Department of Child Health, King's College Hospital, London
}

SUMMARY Forty preterm infants suffering from respiratory distress syndrome were entered into a randomised controlled trial to assess the importance of the length of inspiratory time during weaning from high frequency positive pressure ventilation (HFPPV). Two weaning regimes were compared: in one (group A) inspiratory time was limited to 0.5 seconds throughout weaning, in the other (group B) ventilator rate was reduced by increasing both inspiratory and expiratory time (inspiration:expiration ratio constant) until inspiratory time reached 1.0 seconds. At ventilator rates of 20 and 40 breaths/minute an acute comparison was made in all 40 infants of the two inspiratory times; despite the lower mean airway pressure associated with the shorter inspiratory time blood gases were maintained. There was no difference in the incidence of pneumothoraces or need for reventilation between the two regimes but infants in group A had a shorter duration of weaning. We conclude limitation of inspiratory time to 0.5 seconds during weaning from HFPPV is advantageous to preterm infants with respiratory distress syndrome.

High frequency positive pressure ventilation (HFPPV), defined as rates of 60 breaths/minute or greater, has recently been used for preterm neonates with great success. ${ }^{1}$ HFPPV has been associated with a reduction in the incidence of pneumothoraces, both in trials involving retrospective or non-randomised controls ${ }^{2-4}$ and more recently in a multicentre randomised controlled trial. $^{5}$ Physiological studies have shown that fast rates reduce active expiration, ${ }^{67}$ a respiratory interaction that precedes the development of pneumothoraces, ${ }^{8}$ thus supporting the clinical findings. ${ }^{2-5}$ In the acute stage of respiratory distress syndrome, the infants' spontaneous respiratory rates are inversely proportional to their gestational ages. ${ }^{9}$ Thus when fast rates are used for very immature infants, synchronous respiration is induced and oxygenation improved. ${ }^{10}$

At fast rates, inspiratory time is necessarily reduced. This limitation of inspiratory time may be one explanation for the success of HFPPV, as prolongation of inspiratory time certainly has been shown to increase both the incidence of pneumothoraces ${ }^{11}$ and of active expiration. ${ }^{12}$ In a recent short term study we found that limiting the inspiratory time to 0.5 seconds during the weaning process from HFPPV was also advantageous. ${ }^{13}$ It was associated with a reduction in active expiration and a significant increase in minute volume when compared with the effects of a longer inspiratory time. ${ }^{13}$ Weaning from HFPPV, however, is only initiated during recovery from respiratory distress syndrome, and during this phase the lungs become more compliant resulting in an increased time constant of the respiratory system. ${ }^{14} \mathrm{~A}$ tenable argument, therefore, would be that during weaning the inspiratory time should be prolonged as the rate is reduced in order to ensure maximum inflation and oxygenation and thus prevent the development of atelectasis. The aim of this study was to investigate, by means of a randomised controlled trial, if the length of inspiratory time was an important determinant of the duration of weaning from HFPPV.

Patients and methods

METHODS

Infants were eligible for inclusion in the study, if suffering from respiratory distress syndrome and ventilated at rates in excess of 60 breaths/minute. In all instances we had followed our usual weaning protocol, in which both rate and peak inspiratory 
pressure were reduced until a ventilator rate of 60 breaths/minute and a peak inspiratory pressure of 20 cm $\mathrm{H}_{2} \mathrm{O}$ were reached.

Subsequently weaning from ventilation was attempted solely by reducing the rate while peak inspiratory pressure was held constant. When the ventilator rate reached 20 breaths/minute aminophylline or theophylline were administered either intravenously or orally. ${ }^{15}$ At ventilator rates of 60 breaths/minute infants were entered into the study and randomised to weaning groups $\mathrm{A}$ or $\mathrm{B}$ : in group $A$ the ventilator rate was reduced by increasing expiratory time only, inspiratory time was held constant at 0.5 seconds; in group B the ventilator rate was reduced by increasing both inspiratory and expiratory time (the inspiration: expiration ratio being held constant at $1: 1.2$ ) until the inspiratory time reached 1.0 seconds. Subsequently the rate was reduced by increasing the expiratory time only. In every other respect the protocol for weaning from ventilation was similar in both groups, in particular the criteria used for altering ventilator rate and reintubation.

All changes in ventilator settings were made by the clinical team caring for the infants. Throughout weaning, the infants' oxygen pressure was continuously monitored, either by a transcutaneous electrode or a Searle intra-arterial electrode. During weaning blood gases were measured as clinically indicated and routinely every four hours. Ventilator rate was reduced only if either the infant had developed a respiratory alkalosis or the blood gases had been maintained over the four hour period. The inspired oxygen concentration was reduced if the arterial oxygen pressure exceeded $7 \cdot 3 \mathrm{kPa}$, regardless of whether a reduction in ventilator rate was made. After a change in ventilation the arterial blood gases were checked within 40 minutes, and further ventilator rate reduction made if the infant had a persisting respiratory alkalosis. Ventilator rate reduction was made in steps of ' 5 breaths/minute', until the infant was receiving endotracheal continuous positive airways pressure (CPAP). Arterial blood gases were checked after the infant had been receiving CPAP for one hour and if there was no evidence of a respiratory acidosis $(\mathrm{pH}<7 \cdot 25)$ the infant was then extubated.

Mean airway pressure is related to the length of inspiratory time ${ }^{16}$ and when related to ventilator rate it differed between the two regimes (fig 1). To compare the two regimes, therefore, two separate comparisons were made:

(1) Comparison of the short term effects of changes in inspiratory time

All infants at ventilator rates of 40 and 20 breaths/

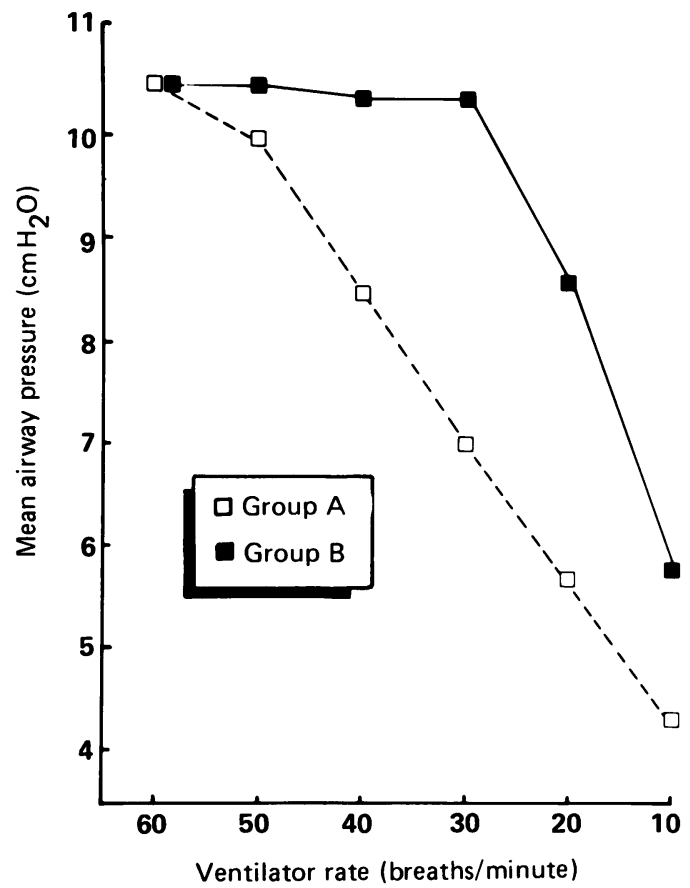

Fig 1 Mean airway pressure during weaning associated with the limited inspiratory time (group A) compared with the longer inspiratory time (group B) related to ventilator rate.

minute were studied at the inspiratory time of both regimes for 30 minute periods; the inspired oxygen concentration was held constant during this comparison. At the end of each 30 minute period arterial oxygen and carbon dioxide pressures, $\mathrm{pH}$, and base deficit were compared. After this one hour period study the infant was then returned to the original randomised regime.

\section{(2) Comparisons of the longer term effects of changes in inspiratory time}

The duration of weaning, the number of pneumothoraces and need for reventilation were compared between the infants randomised to the two regimes. The duration of weaning was defined as the time from entering the study until first extubation. Reventilation was any episode of reintubation and ventilation after first extubation.

TRIAL SIZE

Using results derived from 20 infants previously ventilated on our unit we calculated that a trial population of 40 infants was necessary to detect with $85 \%$ power at the $5 \%$ level a significant difference 
of 24 hours in the duration of weaning between the two groups.

\section{STATISTICAL ANALYSIS}

To determine if differences between the two groups and inspiratory times were significant either a Fisher's exact test or Wilcoxon rank sum test was used.

\section{PATIENTS}

Twenty patients were randomised to both groups A and $B$. All the patients were suffering from respiratory distress syndrome, as evidenced by the development of respiratory symptoms within four hours of birth that persisted for longer than 24 hours, initially in the absence of infection. The infants' chest radiographs showed a symmetrical reticulogranular pattern and an air-bronchogram. The infants were ventilated by oroendotracheal tubes using a continuous flow, variable pressure ventilator (Sechrist). There was no significant difference in the gestational age, postnatal age, or sex distribution between the two groups (table 1). Neither was there a significant difference in the number of infants in each group

Table 1 Clinical details of patients at trial entry. Results are mean (range)

\begin{tabular}{lll}
\hline & Group A & Group B \\
\hline Gestational age (weeks) & $28 \cdot 5(24-32)$ & $28 \cdot 0(24-32)$ \\
Postnatal age (days) & $4 \cdot 1(2-14)$ & $3 \cdot 9(1-11)$ \\
Males & 11 & 15 \\
Before weaning: & 2 & \\
$\quad$ Pneumothoraces & 5 & 1 \\
Patent ductus arterious & 3 & 4 \\
Pneumonia & & 4 \\
\hline
\end{tabular}

who, before weaning, had developed pneumothorax, patent ductus arteriosus, or pneumonia. Pneumonia was characterised by asymmetrical consolidation on the chest radiograph and isolation of bacteria from a tracheal aspirate in a previously non-infected infant.

One infant, a girl of 24 weeks' gestation, randomised to group A, developed necrotising enterocolitis during the weaning process and died. The results of the 39 infants who completed the trial are presented.

Ethical permission for this study was granted by the King's College ethics committee.

\section{Results}

At neither ventilator rates of 20 nor 40 breaths/ minute were arterial blood gases significantly different at the inspiratory times of the two regimes (table 2).

The duration of weaning was significantly shorter in group A than group B. The mean duration was 110 hours (range 11-485) in group $A$ and 224 hours (range $14-864)$ in group B $(\mathrm{p}<0.01)$ (fig 2). Only two infants developed pneumothoraces during the weaning process, both of these infants were in group $B$, and two infants from each group developed a patent ductus arteriosus during the weaning process; all responded to medical management. There was no significant difference in the number of infants who required reventilation in the two groups: there were four in group $\mathbf{A}$ and eight in group B.

\section{Discussion}

In the acute comparison, despite a lower mean airway pressure when related to ventilator rate,

Table 2 Arterial blood gases and inspired oxygen concentrations at two inspiratory times at 40 and 20 breaths/minute. Results are mean (range)

\begin{tabular}{|c|c|c|c|c|c|c|c|c|}
\hline & \multicolumn{4}{|c|}{ Ventilator rate 40 breaths/minute } & \multicolumn{4}{|c|}{ Ventilator rate 20 breaths/minute } \\
\hline & \multicolumn{2}{|l|}{ Group $A$} & \multicolumn{2}{|l|}{ Group B } & \multicolumn{2}{|l|}{ Group $A$} & \multicolumn{2}{|l|}{ Group B } \\
\hline & $0 \cdot 5$ & $0 \cdot 7$ & $0 \cdot 7$ & $0 \cdot 5$ & $0 \cdot 5$ & $1 \cdot 0$ & $1 \cdot 0$ & $0 \cdot 5$ \\
\hline Arterial oxygen & & & & & & & & \\
\hline pressure (kPa) & $\begin{array}{l}8 \cdot 7 \\
(6 \cdot 4-9 \cdot 7)\end{array}$ & $\begin{array}{l}8 \cdot 4 \\
(7 \cdot 2-10 \cdot 0)\end{array}$ & $\begin{array}{l}8 \cdot 0 \\
(5 \cdot 2-9 \cdot 3)\end{array}$ & $\begin{array}{l}8 \cdot 3 \\
(6 \cdot 4-14 \cdot 6)\end{array}$ & $\begin{array}{l}8 \cdot 9 \\
(7 \cdot 6-10 \cdot 9)\end{array}$ & $\begin{array}{l}8 \cdot 6 \\
(7 \cdot 6-10 \cdot 4)\end{array}$ & $\begin{array}{l}9 \cdot 1 \\
(7 \cdot 2-11 \cdot 5)\end{array}$ & $\begin{array}{l}8 \cdot 7 \\
(7 \cdot 5-14 \cdot 4)\end{array}$ \\
\hline $\begin{array}{l}\text { Arterial carbon dioxide } \\
\text { pressure }(\mathrm{kPa})\end{array}$ & $\begin{array}{l}5 \cdot 3 \\
(3 \cdot 9-6 \cdot 3)\end{array}$ & $\begin{array}{l}4 \cdot 9 \\
(4 \cdot 4-6 \cdot 0)\end{array}$ & $\begin{array}{l}5 \cdot 6 \\
(3 \cdot 9-6 \cdot 7)\end{array}$ & $\begin{array}{l}5 \cdot 2 \\
(4-6 \cdot 3)\end{array}$ & $\begin{array}{l}5 \cdot 2 \\
(4 \cdot 4-6 \cdot 7)\end{array}$ & $\begin{array}{l}4 \cdot 8 \\
(3 \cdot 7-5 \cdot 7)\end{array}$ & $\begin{array}{l}5 \cdot 6 \\
(3 \cdot 9-7 \cdot 2)\end{array}$ & $\begin{array}{l}5 \cdot 6 \\
(3 \cdot 5-6 \cdot 5)\end{array}$ \\
\hline \multirow[t]{2}{*}{$\mathrm{pH}$} & $7 \cdot 32$ & $7 \cdot 33$ & $7 \cdot 34$ & $7 \cdot 31$ & $7 \cdot 32$ & $7 \cdot 34$ & $7 \cdot 33$ & $7 \cdot 33$ \\
\hline & $(7 \cdot 27-7 \cdot 46)$ & $(7 \cdot 23-7 \cdot 40)$ & $(7 \cdot 28-7 \cdot 40)$ & $(7 \cdot 23-7 \cdot 35)$ & $(7 \cdot 25-7 \cdot 42)$ & $(7 \cdot 30-7 \cdot 40)$ & $(7 \cdot 25-7 \cdot 40)$ & $(7 \cdot 28-7 \cdot 39)$ \\
\hline Base deficit & $\begin{array}{l}4 \cdot 8 \\
(1 \cdot 2-8 \cdot 5)\end{array}$ & $\begin{array}{l}5 \cdot 3 \\
(0 \cdot 1-7 \cdot 9)\end{array}$ & $\begin{array}{l}4 \cdot 6 \\
(1 \cdot 6-12 \cdot 6)\end{array}$ & $\begin{array}{l}6 \cdot 6 \\
(2 \cdot 1-8 \cdot 5)\end{array}$ & $\begin{array}{l}5 \cdot 6 \\
(3 \cdot 2-7 \cdot 5)\end{array}$ & $\begin{array}{l}4.9 \\
(0.8-8 \cdot 5)\end{array}$ & $\begin{array}{l}6 \cdot 0 \\
(2 \cdot 3-11 \cdot 5)\end{array}$ & $\begin{array}{l}5 \cdot 4 \\
(1 \cdot 1-12 \cdot 0)\end{array}$ \\
\hline \multicolumn{6}{|l|}{ Fractional inspiratory } & $31(21-40)$ & \multicolumn{2}{|c|}{$28(21-45)$} \\
\hline
\end{tabular}




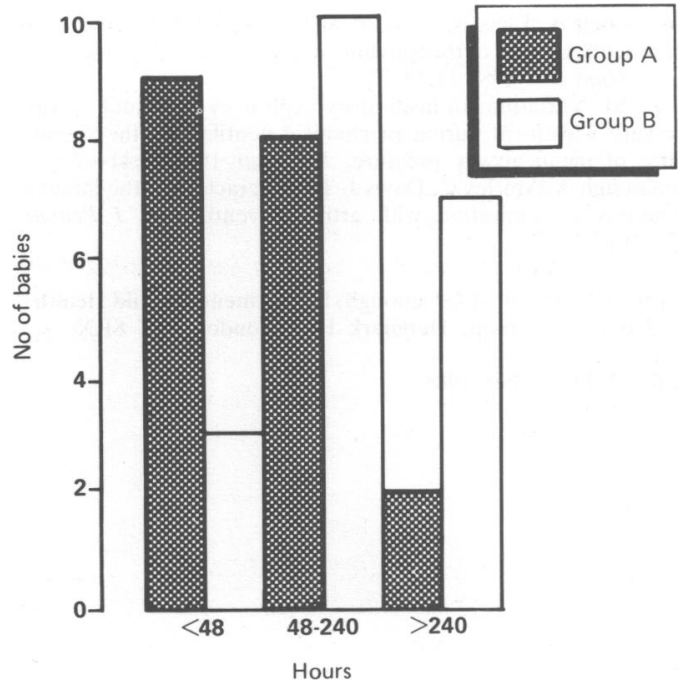

Fig 2 The number of infants in groups $A$ and $B$ extubated in each of three time periods.

oxygenation was maintained at the shorter inspiratory time. Mean airway pressure has previously been shown to be an important determinant of oxygenation. ${ }^{16}$ That study, however, included ventilated and paralysed infants, and among infants capable of making appreciable, spontaneous respiratory effort mean airway pressure is unlikely to be the only determinant of oxygenation. In our short term weaning study we found that limiting the inspiratory time resulted in an increase in minute volume and a reduction in active expiration; both of these factors would tend to improve oxygenation. ${ }^{9}$

During this study only two infants developed a pneumothorax, both in group B. This pneumothorax rate is perhaps surprisingly low as we would predict, using the results of our short term study, ${ }^{13}$ that the infants in group B would all be expiring actively, and hence at risk of developing an airleak. ${ }^{17}$ We have, however, only shown a significant association with pneumothorax when active expiration is seen during the acute stage of respiratory illness, in infants who are being 'fully' ventilated. ${ }^{817}$ The present results suggest that infants, with more compliant lungs being ventilated at a reduced rate, even when actively expiring, may not be at risk of developing an air leak.

In group $\mathbf{A}$ a smaller number of infants required to be reintubated thus suggesting that the limited inspiratory time was sufficiently long to prevent the development of atelectasis during weaning. During ventilation expiratory time must be long enough to allow complete lung deflation, particularly at fast rates. ${ }^{4}$ In both groups, as ventilator rate was reduced, the expiratory time was longer than the inspiratory time. Although in group B the expiratory time, at each ventilator rate, was shorter than in group $\mathbf{A}$, there was no difference in carbon dioxide concentrations during the acute comparison, suggesting the expiratory time was adequate in both groups.

Although this study was randomised it was not possible to 'blind' the clinicians as they could determine from the ventilator settings the randomisation group of the infant. During the months in which the study was carried out, a number of doctors were involved, it seems unlikely that all were biased to one particular regime. All infants entered into the study followed our routine weaning policy, which, as described earlier, clearly instructs the method of ventilator rate reduction expected, this again reduces the possibility of bias.

We have shown a reduced frequency of reintubation and a shorter duration of weaning amongst infants in group A. These results confirm that limitation of inspiratory time during weaning is advantageous to preterm infants.

Sister $\mathbf{J}$ Pool is supported by Children Nationwide Medical Research Fund. We thank the staff of the neonatal intensive care unit without whose enthusiatic help this study would not have been possible.

\section{References}

${ }^{1}$ Greenough A, Milner AD. High frequency ventilation in the neonatal period. Eur J Pediatr 1987;146:446-9.

${ }^{2}$ Bland RD, Kim MH, Light MJ. High frequency mechanical ventilation in severe hyaline membrane disease: an alternative therapy? Crit Care Med 1980;8:275-80.

${ }^{3}$ Heicher DA, Kastings DS, Richards JR. Prospective clinical comparisons of two methods for mechanical ventilation of neonates: rapid rates and short inspiratory time versus slow rate and log inspiratory time. $J$ Pediatr 1981;98:957-81.

${ }^{4}$ Greenough A, Dixon AD, Roberton NRC. Pulmonary interstitial emphysema. Arch Dis Child 1984;19:1046-61.

5 Pohlandt $\mathrm{F}$, Bernsau V, Feilen $\mathrm{KD}$, et al. Reduction in barotrauma in ventilated neonates by increase in ventilation frequency. First results of a prospective collaborative and randomised trial of two different ventilator techniques. Pediatr Res 1985;19:1077.

${ }^{6}$ Field DJ, Milner AD, Hopkin IE. Inspiratory time and tidal volume during intermittent positive pressure ventilation. Arch Dis Child 1985;60:259-61.

7 Greenough A, Morley CJ, Pool JB. Fighting the ventilatorare fast rates an effective alternative to paralysis? Early Hum Dev 1986;143:189-94.

${ }^{8}$ Greenough A, Wood S, Morley CJ, Davis JD. Pancuronium prevents pneumothoraces in ventilated premature babies who actively expire against positive pressure ventilation. Lancet 1984;i:1-4.

9 Greenough A, Greenall F, Gamsu H. Synchronous respiration; which ventilator rate is best? Acta Paediatr Scand 1987;76: 713-8. 


\section{Greenough, Pool, and Gamsu}

${ }^{10}$ Greenough A, Pool J, Greenall FM, Morley CJ, Gamsu H. Comparison of different rates of artificial ventilation in preterm neonates with respiratory distress syndrome. Acta Paediatr Scand 1987;76:706-12.

11 Primak PA. Factors associated with pulmonary airleak in premature infants receiving mechanical ventilation. $J$ Pediatr 1983;102:764-8.

12 Greenough $A$. The premature infant's response to mechanical ventilation. Early Hum Dev 1988;17:1-5.

${ }^{13}$ Greenough A, Greenall FM, Gamsu H. Inspiratory times when weaning from mechanical ventilation. Arch Dis Child 1987;62:1269-70.

${ }^{14}$ Ramsden CA, Reynolds EDR. Ventilator settings for newborn infants. Arch Dis Child 1987;62:529-38.
15 Greenough A, Elias-Jones A, Pool J, Morley CJ, Davis J. The therapeutic actions of theophylline in preterm ventilated infants. Early Hum Dev 1985;12:15-22.

${ }^{16}$ Boros SJ. Variations in inspiratory:expiratory ratio and airway pressure waveform during mechanical ventilation: the significance of mean airway pressure. J Pediatr 1979;94:114-7.

17 Greenough A, Morley C, Davis J. The interaction of the infant's spontaneous respiration with artificial ventilation. J Pediatr 1983;103:769-73.

Correspondence to Dr A Greenough, Department of Child Health, King's College Hospital, Denmark Hill, London SE5 8RX.

Accepted 1 December 1988 